and the difficulty of reading without affecting their record; but this I completely got over as explained in my "Visit to South America," I878, by using a simple whirling table, on which the thermometers were fixed, the reading being effected by bringing them in succession under a plate of glass covering part of the circumference of the table. Nothing can exceed the simplicity of such an arrrangement, which is almost independent of position, and with small thermometers affords a uniformity and accuracy impossible of attainment with a fixed thermometer, as it becomes a repeating instrument by a few extra turns of the table, thus insuring freedom from error of observation. I have used this system for many years with most satisfactory results.

EDWIN ClaRK

\section{Science and the Public Service}

WHILST sincerely regretting the new scheme of openly cutting down the science marks in the army examinations, I think it is not so much the low maximum of marks supposed to be attainable which is discouraging the science subjects, as the low marks actually given at all Government examinations (excepting the Indian Woods and Forests) to any one who is so unwise as to take up natural science. To take, as an example, the Indian Civil Service marks of last year. While in French and German, each of which is a 500 subject, more than 30 per cent. of the candidates obtained over 200 marks; in chemistry, which is also a 500 subject, only two out of thirty-two, or 6 per cent. scored over 20o. The marks in the other subjects included in the fatal column of natural science are equally low. Now I do not think that any one will maintain that science is not properly taught at Clifton, Dulwich, \&c., yet in French and German a boy has every chance of obtaining 100 marks more than in chemistry (the highest marks last year were-chemistry 229, French 325, German 347). Two possibilities present themselves : either the clever boys will not take up science subjects at all owing to the low marks persistently given, or the examiners expect more chemical knowledge from a boy of eighteen (who must take mathematics or classics, English, \&c., in addition to chemistry) than he can possibly acquire. I trust that examiners may be induced to seriously consider the last possibility.

$$
\text { F. C. S. }
$$

\section{THE ROYAL CORPS OF NAVAL CONSTRUCTORS}

$\mathrm{BY}$ an Order in Council of August last this corps was established; an Admiralty Circular of November last published the details of the new arrangements; and the result of the first examination for the grade of "Students in Naval Construction" has recently been announced. An important change has thus been made in the entry, training, and promotion of the professional officers upon whom devolve the responsibilities connected with the design and construction of ships for the Royal Navy ; yet little public interest has been evinced. There can be no dispute, of course, as to the great importance attaching to the maintenance in the highest state of efficiency of the constructive department of the navy. Shipbuilding is making such rapid strides that all who have to take part in its developments, whether for war or for commerce, require a highly scientific as well as a thoroughly practical education, if they desire to keep in the forefront of progress. And for modern war-ships with their high speeds, heavy burdens of armour and armament, and liability to damage in action, specially difficult problems continually present themselves, the solution of which is only possible by means of scientific procedure. Recognising these facts, it may be well to make a brief statement respecting the new Constructive Corps, and to indicate the manner in which its creation may be beneficial not merely to the public service but to the mercantile marine.

It is only proper to remark at the outset that the Lords Commissioners of the Admiralty have hitherto been the chief patrons of the scientific education of shipbuilders in England; and to their generosity has been due the existence of the only establishments in which the higher train- ing of naval architects was provided for. Early in the present century (18II) the first School of Naval Architecture was established in Portsmouth Dockyard, and continued at work for more than twenty years. It was established in consequence of the absolute necessity for opposing to the well-trained French naval architects men of equal education and ability, who could not be found at that time in our naval service. Ship-designing was clearly in a very inferior position here, when no shame was felt in building servile imitations of vessels captured from the French. In 1832 this school was abolished, and for sixteen years there was no training establishment of the kind open for English students. But during that interval men educated at Portsmouth occupied important positions both in the Royal Naval service and in private establishments, helping to maintain our national reputation. In I 848 a second school was opened at Portsmouth, on a much more modest scale, and destined to have a shorter life, for it lasted only five years. That brief period sufficed, however, to produce a number of men still holding some of the highest positions in the profession. Another interval of ten years elapsed, and then the Royal School of Naval Architecture was opened at South Kensington, the Admiralty giving it large support, although it aimed at educating other than Admiralty students. Since I 864 there has been no interruption in the good work, although in 1873 the establishment at Kensington was broken up, and the Admiralty section of it transferred to the Royal Naval College at Greenwich. There, as at Kensington, all comers are welcomed if they possess sufficient preliminary training, and private English students, as well as foreigners, have opportunities for instruction afforded them as good as those which the Admiralty provide for their own students. By the munificence of Mrs. John Elder the University of Glasgow has had a Professorship of Naval Architecture recently established, and the classes will, it is understood, commence work this year. But up to the present time the Royal Naval College affords unrivalled opportunities for instruction, and may challenge comparison with any similar institution in Europe.

By means of the very excellent training schools in the Royal dockyards, and the large field of selection from among the apprentices, the Admiralty have been able to secure a continuous supply of well-prepared students for the higher training at Kensington or Greenwich ; and thus have obtained the educated naval architects required for the public service. Nor is this all that has been done. A very considerable number of the trained men have passed from Admiralty employment into private establishments, where they have done and are doing good work.

It may be asked, in view of these results, why change a system which has worked so well? The answer is twofold. First, there were grave objections to the continuance of the restrictions imposed by the regulations for first entry into the service. Second, there was not proper recognition of the special training which a student had received when he passed out into actual work, nor any guarantee of a subsequent career. These points require brief explanation.

Although the Admiralty so fully recognised the value of scientific training for its naval architects, and made provision for it, yet for half a century they maintained regulations which necessitated the first entry into the service being made either as an apprentice or as a working man. A few exceptions may be quoted: but the general rule was as stated. The result of this arrangement was that, with few exceptions, candidates for entry came from the working classes; and there was no attraction into the service of the sons of persons in good social positions, such as very commonly become pupils of civil or mechanical engineers. This was obviously a matter which required alteration. The competition for entry was absolutely free, no doubt; but it was surrounded by conditions which 